\title{
Los arbitristas y la América portuguesa (1590-1640)/
}

\author{
The Arbitristas and the colonial Brazil \\ (1590-1640)
}

\section{Vinicius Dantas}

Centro de História d'Além-Mar

Universidade Nova de Lisboa

Este artículo reflexiona sobre el papel de los arbitristas y de sus escritos en el gobierno y la conservación del Brasil durante el período de la unión de las coronas ibéricas. A pesar de la existencia de una historiografía sobre los arbitristas en Portugal, la investigación ha concedido poca importancia al estudio de los arbitrios referidos a la América portuguesa.

Palabras Clave: Arbitristas; Brasil Colonial; Portugal; Unión Ibérica; Cultura Política; Siglo XVII.

This article reflects on the role of the arbitristas (projectors) and their writings in the government and conservation of Brazil, during the union of Iberian crowns. Despite the existence of a historiography on the arbitristas in Portugal, historians have paid little attention to the study of the arbitrios about colonial Brazil.

Keywords: Arbitristas; Colonial Brazil; Portugal; Iberian Union; Political Culture; Seventeenth Century. 


\section{VINICIUS DANTAS}

\section{Introducción}

A finales de diciembre de 1640, los consejeros de Estado de Felipe IV se reunieron en Madrid para discutir las medidas a seguir para proteger a las Indias Occidentales. Con la secesión de los vasallos lusos y la aclamación del duque de Braganza como Juan IV a principios de ese mes, el rey católico y sus ministros más cercanos quedaron temerosos ante la posibilidad de que el ejemplo de la «rebelión» de Portugal se propagara por las posesiones americanas de la monarquía hispánica, en especial a través de la ciudad de Buenos Aires.

En aquel momento, los consejeros del cuarto Felipe compartían la opinión de que era esencial defender aquel puerto, fundamentalmente por su vecindad geográfica con la América portuguesa. En este sentido, entendían que el reconocimiento de Juan IV por los vasallos de Brasil ponía en riesgo la autoridad de Felipe IV en las posesiones vecinas. ${ }^{1}$ A pesar del mantenimiento de la fidelidad de los súbditos del monarca español en la región del Plata, los vasallos del Brasil reconocieron el nuevo gobierno del duque de Braganza con poca resistencia. De hecho, el rey portugués fue aclamado en distintas regiones de la América lusa, lo que restauró la antigua división entre las posesiones ultramarinas de Portugal y Castilla. ${ }^{2}$

Felipe IV, sin embargo, pareció rechazar de plano la pérdida de los territorios americanos que reconocieron a los «rebeldes». En abril de 1641 escribió al obispo de Brasil y a los representantes de la ciudad de Salvador de Bahía, en un último intento por impedir que los «desordens e extorções» de los «sediciosos» de Portugal llegasen a las posesiones de origen luso y se extendiesen por las Indias Occidentales. Sin atender a los clamores por la conservación de la «fidelidad» de los vasallos, el Estado do Brasil escapó finalmente de la autoridad de los Austrias. ${ }^{3}$

1 Archivo General de Simancas (AGS), Estado, 2664, Consulta del Consejo de Estado, 29 de diciembre de 1640. Como señaló Oscar Trujillo, la rebelión de Portugal inició un conflicto entre la corona española y la elite bonaerense. A pesar de las medidas de Felipe IV para aislar a los portugueses de Buenos Aires, los lusos estaban integrados en la elite bonaerense, lo que provocó la resistencia de diversos sectores contra la persecución. Trujillo, 2009, 333-350 y 2013, 249-269; Ceballos, 2008, 253-280. Agradezco al doctor Alberto Baena la revisión del texto en español y sus sugerencias, y también a los evaluadores anónimos por sus valiosos comentarios.

2 Barros, 2008, 94-98; Valladares, 1993, 151-172 y 1998, 32-36; Monteiro, 2002, 35-72; Relação, 1641.

3 Biblioteca Nacional de España (BNE), Mss. 3014, Carta de Felipe IV para o bispo do Brasil, custodio de São Francisco e provinciais das outras ordens daquele Estado, 20 de abril de 1641, 333-339; BNE, Mss. 3014, Carta de Felipe IV para a câmara da cidade de Salvador na Bahia, 20 de abril de $1641,335-336$. 
En suma, en aquel atribulado año de 1640 la reputación de la monarquía hispánica resultó severamente afectada por la pérdida de la América portuguesa. En este caso, la derrota impuesta al cuarto Felipe y a su valido, el conde-duque de Olivares, no había sido provocada por la acción de sus rivales ingleses y holandeses, que le disputaban la hegemonía de los mares. Más bien, resultó una consecuencia directa de las rebeliones experimentadas dentro del propio mundo ibérico, cuando el monarca español y su principal ministro constataron la respuesta colectiva dada por los reinos agregados al nuevo modus operandi que intentaron imponer. ${ }^{4}$

Ahora bien, si la pérdida del Estado do Brasil fue provocada por las decisiones políticas de Felipe IV y de Olivares, resulta interesante formular los siguientes interrogantes: ¿qué consejos recibieron de sus vasallos para la conservación de aquel territorio?, ¿cuál fue el papel de los arbitristas que remitieron sus informes a los monarcas españoles y a sus privados para la conservación de la América lusa?

Este artículo reflexiona sobre la cuestión del arbitrismo referido a la América portuguesa, en el período comprendido entre los últimos años del reinado de Felipe II hasta la secesión de 1640. En la primera parte del texto se examina el origen y la difusión del concepto arbitrismo, así como también las imágenes que sobre los arbitristas circulaban en Portugal. En la segunda parte se estudia el nacimiento de una reflexión arbitrista respecto de los problemas de las conquistas portuguesas, que se desarrolló con el ejemplo de las Indias Orientales y se discute un importante repertorio de arbitrios sobre la América lusa correspondientes al período señalado.

No obstante la importancia de los trabajos sobre el fenómeno arbitrista en Portugal, el estudio del arbitrismo americano de origen luso todavía no ha alcanzado el mismo interés historiográfico. ${ }^{5}$ Para comprender este tema en toda su complejidad resulta necesario conocer el papel de los arbitrios en la cultura política portuguesa del siglo XVII, señalando sus similitudes y sus diferencias respecto del caso español.

4 Para una interpretación general de los problemas de la monarquía hispánica en el año de 1640: Elliott, 2009, 551-642; Parker, 2006, 55-103.

5 Listamos aquí los principales trabajos sobre el arbitrismo en Portugal: Amzalak, 1922a, 5-16; Amzalak, 1922b; Sérgio, 1974, 3-26; Godinho, 1980; Oliveira, 1982; Winnius, 1985; Cruz, 1988; Amorim, 1988; Curto, 1988a, 1988b, 1998, 2009, 2011a y 2011b; Oliveira, 1990; Rebelo, 1991-1992; Coelho, 1995 y 1996; Schaub, 1993 y 2001; Flores, 2001; Frutuoso, 2007; Martínez Torres, 2012. En la historiografía sobre el Brasil algunos autores discutieron indirectamente textos arbitristas, como por ejemplo: Cabral de Mello, 2007. Para una aportación reciente sobre el tema del arbitrismo en la América portuguesa: Marques, 2009b, 138-146. 


\section{El origen del «alvitrismo» y su significado en la Corona portuguesa}

A principios del siglo XVII, las palabras arbitrio, alvitre y alvítrio eran usadas en la lengua portuguesa en contextos distintos. En primer lugar, un alvitre podía referirse a un consejo para la resolución de algún asunto; ${ }^{6}$ también podía ser una merced concedida por los monarcas para la explotación de un género monopolizado, como por ejemplo el alvitre de la pimienta. ${ }^{7}$ Finalmente designaba a un proyecto para la solución de un negocio específico de un reino o un imperio. En ese último caso, el alvitre era entendido en su materialidad, es decir, como un texto de exposición de ideas para el tratamiento de algún problema concreto del gobierno de la monarquía y de sus conquistas. ${ }^{8}$ En Portugal, los que presentaban este tipo específico de recomendaciones eran conocidos como arbitristas, alvitristas, Alvitreiros, Alvitrador o Arbitrador. ${ }^{9}$

Aunque está claramente constatado el uso del concepto en la primera mitad del siglo XVII, resulta complicado delimitar el momento de su difusión en la lengua portuguesa. Otras dificultades consisten en determinar la fecha en la que aparecieron los primeros alvitres, o el momento en el que nació el alvitrismo como un «género» del discurso político. No obstante, es posible reflexionar sobre los cambios que contribuyeron a la afirmación del arbitrismo como una nueva forma de literatura política usada para la resolución de los problemas concretos de la monarquía portuguesa y de sus espacios ultramarinos.

El arbitrismo luso parece haber tenido su origen en los años anteriores a la incorporación de Portugal a los dominios de la monarquía hispánica, siendo contemporáneo a su surgimiento en otras monarquías europeas. Una de las posibles influencias para ese género de advertencias eran los pareceres y los memoriales que, desde el final de la Edad Media hasta la primera mitad del siglo XVI, los monarcas lusos solicitaban a sus privados. Estos papeles podían ser debatidos en el consejo regio o responderse personalmente por el rey a su autor. ${ }^{10}$ Por ejemplo, en la década de 1530 el rey

6 Pereyra, 1647, 9 v.; Bluteau, I, 1716, 469.

7 Morais Silva, I, 1789, 112.

8 Bluteau, I, 1716, 308.

9 Ibidem, 308-309 y 469.

10 Ejemplos de los pareceres medievales: Conselho dado por D. Fernando, marquês de Vila Viçosa, a el-rei D. Afonso V sobre aliança com cavaleiros de Castela contra Henrique IV ou com o soberano de Aragão e sobre a prossecução da guerra em Marrocos, 17 de junio de 1460, en Monumenta 
Juan III solicitó opinión a sus ministros para obtener distintos pareceres acerca de la política que debía seguirse en el Norte de África. Cerca de cuatro años después, el monarca recibió otras propuestas respecto de la conservación o la entrega de las ciudades de Safin y Azamor a los moros, que incidieron directamente en sus decisiones. ${ }^{11}$ A lo largo de la Edad Moderna, tales recomendaciones permanecieron como una práctica para la tramitación de los consejos, conviviendo con los arbitrios remitidos por desconocidos al monarca y a sus ministros.

Pese a las similitudes entre el estilo predominante en los pareceres de los consejeros de los primeros años del siglo XVI y los alvitres de la segunda mitad, lo cierto es que estos últimos parecen haber sido el resultado de un proceso histórico más amplio. El surgimiento de los arbitristas en Portugal señaló la ampliación del espacio de participación política. En este período, la práctica de enviar consejos, memoriales y advertencias al monarca dejó de ser un privilegio de los consejeros y teólogos que componían el entourage del príncipe, difundiéndose por todo el reino y el imperio. ${ }^{12}$ En este sentido, los arbitristas expusieron sus propias ideas y sus opiniones sin orden de los soberanos o de sus privados. ${ }^{13}$

La ampliación del derecho a opinar en las materias políticas del reino y de las posesiones ultramarinas, propia del surgimiento del arbitrismo, tuvo como punto de partida la consolidación de una concepción más abstracta de la idea de gobierno, cuando además de asociarse al poder político la persona carismática del príncipe también lo hicieron los conceptos de Estado e Imperio. ${ }^{14}$ En Portugal, esta nueva percepción también fue legitimada por las instituciones, con la creación de un Consejo de Estado y con la emergencia de la figura del secretario de Estado para el tratamiento de los asuntos del «gobierno político». ${ }^{15}$

Henricina, $(M H), 1971,295-310$; Conselhos dados a el rey dom Affonso per algumas pesoas de seus reinos, e primeiro do infante dom Fenando, seu irmão, $M H, 311-323$.

11 Arquivo Nacional da Torre do Tombo (ANTT), Gavetas, Gaveta 2, Maço 7, n. ${ }^{\circ} 3$, Parecer que o infante D. Fernando deu a D. João III a respeito da entrega que queria fazer aos mouros das cidades de Safim e Azamor, 10 de junio de 1534. Ibidem, . $^{\circ}$ 5, Parecer do bispo de Coimbra para D. João III a respeito da entrega de Safim, 12 de junio de 1534. Ibidem, n. ${ }^{\circ}$ 6, Parecer do mestre da ordem de Santiago para D. João III sobre a entrega de Safim e Azamor, 9 de agosto de 1534. Ibidem, n. ${ }^{\circ}$ 7, Parecer de Fernão Vaz de Sampaio para D. João III sobre a entrega de Safim e Azamor, 15 de noviembre 1534. Ibidem, n. ${ }^{\circ}$ 8, Parecer do Visconde para D. João III a respeito da entrega de Safim e Azamor, 5 de noviembre de 1534. Acerca de la discusión sobre las posesiones portuguesas en el Norte de África: Cruz, 1997.

12 Oliveira, 1982, 280-281; Curto, 2011a, 349.

13 Dubet y Sabatini, 2008, 882.

14 Skinner, 2002, 368-413.

15 Gama, 2012; Costa, 2008. 
Además de los cambios conceptuales que permitieron la emergencia del arbitrismo, el fenómeno aumentó por causa de los nuevos debates sobre las razones de Estado, por los planteamientos de autores como Maquiavelo o Bodino, y por la difusión de Tácito. ${ }^{16}$ Los arbitristas portugueses, y en general los arbitristas ibéricos, parecen haber abrazado dos presupuestos teóricos propagados por el autor florentino y por el historiador romano.

En primer lugar, también rechazaban la concepción idealizada del gobierno difundida por los teóricos de los «espejos de príncipes» medievales y renacentistas, manifestando su ambición de decir las cosas como «ellas eran». ${ }^{17}$ Otro ejemplo de la influencia de dichos autores en la producción de los arbitristas que escribieron en el contexto luso fue el uso corriente del concepto «conservación» en los debates acerca de la preservación de las conquistas, popularizado, sobre todo, con la difusión de la obra de Botero a finales del siglo XVI. Como sabemos, el autor italiano había sido un pionero en reflexionar sobre la razón de Estado en torno a la idea de la conservación de los territorios, convirtiéndose en una de las más importantes fuentes de inspiración para los arbitristas ibéricos. ${ }^{18}$

En el contexto de la corona portuguesa, los primeros arbitrios en el sentido «moderno» de la palabra surgieron en la misma época en la que se creó el Consejo de Estado, entre los que se encontraban las «advertencias» al rey D. Sebastião acerca de la reforma de los sínodos de 1563, los pareceres para la institucionalización del monopolio del comercio del pan, o un memorial sobre la reducción de los gastos del reino para el crecimiento de la hacienda real. ${ }^{19}$

\section{La difusión del arbitrismo y la imagen de los arbitristas en el Portugal de los Austrias}

La concepción del arbitrismo como un instrumento de gobierno ya estaba consolidada en Portugal en el reinado de Felipe II. Por ejemplo, en

16 Gutiérrez Nieto, 1986, 264.

17 Curto, 2009, 188-189 y 2011a, 349.

18 Sobre el «paradigma conservativo» de la razón de Estado véase: Borelli, 1993, 63-94. Sobre la influencia de Botero en el arbitrismo ibérico: Elliott, 1977, 54-55; Godinho, 1980, 107; Curto, 2011a, 347-400; Gil Pujol, 2003, 969-1022.

19 Bibliothèque Nationale de France, Fonds Portugais (BNF, FP), cod. 8, Memorial sobre a reforma dos conselhos, 149v-152v.; Arbítrio que se propos a el Rey D. Sebastião para ajuntar direito para a jornada de África, 147v.149v.; y Copia da carta que se escreveo ao cardeal estando em Salvaterra, 9 de noviembre de $1563,51-55 \mathrm{v}$. 
una instrucción sobre la navegación en la carrera de la India, el monarca concedió autonomía al conde almirante para remunerar a los autores que presentasen sus propuestas para el aumento de la hacienda real. Según la instrucción,

quando algumas pessoas vos avisarem de alvitres de que minha fazenda receba proveito, sem lhe poder vir por outra via, possaes dar à pessoa que der o tal alvitre o que vos bem parecer do que se arrecadar com efeito para minha fazenda do mesmo alvitre até a quinta parte dele somente, advertindo-vos que o dito alvitre não será de dinheiro ou coisa que esteja em meus livros ou em contas particulares, posto que não estem de presente em notícia de meus oficiais, salvo se com o dito alvitre ter alguma destas circunstâncias a matéria de que ele tratar for tão antiga ou remota que se possa haver por de todo esquecida, porque então poderia chamar alvitre o aviso que disto se der vindo a coisa a efeito de boa arrecadação. ${ }^{20}$

Más tarde, en una carta al virrey de Portugal, el marqués de Alemquer, Felipe IV le comunicó el envío de unos «apontamentos» sobre el arbitrio del conde de la Vidigueira. ${ }^{21}$ Otro testimonio de la difusión del arbitrismo en el Portugal de los Austrias fue presentado por un anónimo luso. En un papel sobre la conversión de los pueblos de Guinea, el autor aludía a los «tantos alvitres» que habían sido presentados al soberano en la década de 1620 , sobre todo para el incremento de la real hacienda. ${ }^{22}$

Los alvitristas lusos tenían diversos orígenes sociales y políticos, ya que entre ellos se encontraban oficiales regios, sacerdotes, militares y autoridades locales. Dentro de este grupo, algunos autores fundamentaron sus argumentos en las informaciones recibidas en la península, mientras que otros habían vivido en Brasil y registraron sus experiencias personales en los textos. ${ }^{23}$

A pesar de su difusión como herramientas de gobierno, los arbitristas no gozaron de buena fama en Portugal. ${ }^{24}$ A principios del siglo XVII, un arbitrista criticó a quienes, como él mismo, remitían papeles al monarca, asegurando que «también los ministros que dan alvitres se deben haber por

20 Instrucção de Felipe II ao conde almirante, 16 de marzo de 1596, en Archivo portuguez. oriental, 1861, 620-621.

21 ANTT, Manuscritos da Livraria, 2267, Carta de Felipe III ao vice-rei Marquês de Alemquer sobre o alvitre do conde da Vidigueira, 11 de octubre de 1617.

22 Biblioteca Nacional de Portugal (BNP), cod. 917, Apontamentos da obrigação que os Reis de Portugal tem de procurarem a conversão dos Povos de Guiné, enero de 1622, 22.

23 Herzog, 2008, 925-928; Marques, 2009, 140-141.

24 Vilar Berrogain, 1973. 
perjudiciales en la república, sin que los admitan en los oficios». ${ }^{25}$ Del mismo modo, en sus Cortes políticas de Apolo, el portugués Agostinho Manuel de Vasconcelos retrató a los alvitreiros como a la gente «mais perniciosa da república». ${ }^{26}$ En la opinión de Vasconcelos, los arbitristas eran los principales responsables de una política poco provechosa para los súbditos en lo relativo a la imposición de tributos, puesto que «não havendo forças, ou razão, que se opuzesse a eles, sendo causados de alvitres de súbditos tão mal intensionados, que procuravam viver da afflicção pública, tirando seus augmentos particulares das calamidades e ruínas dos povos». ${ }^{27}$

Otro ejemplo de la imagen negativa sobre los arbitristas en el Portugal de los Austrias fueron las palabras del portugués Duarte Gomes Solís, que en el prólogo de sus Discursos no escondió su opinión sobre aquellos que enviaban pareceres a la corte madrileña y sus intenciones al proponer remedios para los problemas de la monarquía hispánica: «los arbitristas son tantos en esta corte, que tanto crédito se da a los que tratan las cosas con fundamento, como sin él, si bien la mayor parte de ellos proponen sus arbitrios con su particular interés».28

Como podemos ver, la práctica de remitir arbitrios al soberano ya estaba consolidada en el Portugal de los Austrias. Los arbitristas lusos y los que escribieron en un contexto del mundo portugués presentaban con asiduidad a los Felipes lo que creían que eran los remedios para los problemas del reino, del imperio y de la monarquía católica.

Los alvitres sobre las Indias Orientales y la América portuguesa fueron discutidos en diferentes instituciones, pudiendo pasar o no por los canales tradicionales de decisión política. Con la incorporación lusa a los dominios de la monarquía hispánica y la creación del Consejo de Portugal como principal entidad encargada de los asuntos del reino, las cortes y el Consejo de Estado portugués vieron su papel político reducido. ${ }^{29}$ Los arbitrios generados en Portugal podían ser valorados en el Consejo de Estado luso para una posterior apreciación en el Consejo de Portugal o en el Consejo de Estado de Castilla. Además, las propuestas también podían ser discutidas en las juntas de gobierno creadas para la resolución del asunto

25 Biblioteca Pública de Évora (BPE), CIV-1-19, 3 de febrero de 1607, 4v.

26 ANTT, Casa de Fronteira e Alorna, liv. 21, Cortes políticas de Apolo, 92. Sobre este manuscrito: Curto, 2011b, 473-484.

27 ANTT, Casa de Fronteira e Alorna, liv. 21, «Cortes políticas de Apolo», 98v.

28 Gomez Solís, 1622.

29 Luxán Meléndez, 1988. 
en cuestión, práctica considerada como una subversión de los canales ordinarios de gobierno y discusión política de las monarquías corporativas ibéricas. ${ }^{30} \mathrm{De}$ un modo distinto, los arbitrios podían remitirse al gobernador general de Brasil, para que luego fuesen enviados a Portugal o directamente a Madrid.

Como se deduce de lo dicho hasta aquí, una de las regiones más prometedoras del imperio portugués, el Estado do Brasil, también fue objeto de innumerables arbitrios sobre los problemas que amenazaban su conservación. Sin embargo, a pesar de este manifiesto interés de los arbitristas, el Brasil no fue el centro de las preocupaciones de los que reflexionaron sobre los problemas de las conquistas atlánticas hasta la primera mitad de la década de 1620.

En concreto, la producción de arbitrios sobre la América lusa fue influenciada por coyunturas y situaciones de emergencia, como las invasiones holandesas del noroeste brasileño o, de un modo más amplio, por la llamada «virada atlántica». A partir de la pérdida de las expectativas de recuperación del Estado da Índia, la reflexión se fue focalizando gradualmente en la conservación del Brasil. ${ }^{31}$ De ahí que la comprensión del pensamiento de quienes escribieron sobre las posesiones americanas debe tener en cuenta la importancia de aquel estado y la preocupación por su conservación. Hasta ahora, la historiografía sobre el pensamiento de los arbitristas en Brasil no ha prestado la suficiente atención a esta relación. En el presente trabajo reflexionamos brevemente sobre la cronología de la «virada arbitrista», cuando los numerosos pareceres sobre la recuperación de las Indias Orientales pasaron a coexistir con un creciente número de propuestas para el mantenimiento de Brasil.

\section{Arbitrios en el imperio portugués: de las Indias Orientales al Estado do Brasil}

En 1582, un anónimo portugués concluyó un tratado sobre los oficios y la situación de las fortalezas del Estado da Índia, que fue remitido al recién entronizado Felipe I de Portugal. El autor elaboró una minuciosa descripción «de cada hua das cidades e fortalezas, que V. Mag. ${ }^{\text {de }}$ tem naque-

30 Dubet-Sabatini, 2008, 882; Schaub, 2001, 99-104.

31 Subrahmanyan, 1995. 


\section{VINICIUS DANTAS}

les estados do Oriente, para que visse em verdadeira notícia da grandeza delles». ${ }^{32}$ Sin embargo, cuando anunciaba al rey prudente la «grandeza» de la India, el Estado ya había experimentado sus primeras adversidades económicas y militares. Tales obstáculos dieron origen a una conciencia crítica acerca de los problemas de dicho territorio y de la necesidad de introducir reformas. ${ }^{33}$

La situación de las posesiones portuguesas de ultramar se agravó después de la unión de las coronas ibéricas, cuando los enemigos del rey Felipe se volvieron también contra los antiguos dominios lusos. En el Atlántico, las actividades de corso inglesas, francesas y holandesas en la América portuguesa y en las islas atlánticas cobraron un nuevo rumbo, ${ }^{34}$ mientras que en el Índico la Tregua de los Doce Años (1609-1621), firmada entre españoles y holandeses, no tuvo efecto y fueron corrientes las intervenciones militares en Asia por parte de la Compañía de las Indias Orientales. ${ }^{35}$

Desde principios del siglo XVII hasta por lo menos el año de 1630, la preocupación por los territorios orientales había ocupado un lugar central en Lisboa. Las informaciones acerca de la necesidad de socorrer el Estado da Índia fueron exhaustivamente transmitidas a los monarcas españoles y a sus validos a través de dos medios principales. En primer lugar, por la correspondencia remitida al Consejo de Estado en Madrid o al Consejo de Portugal. ${ }^{36}$ En segundo, por los informes y los arbitrios que llegaban directamente al conocimiento del rey español. ${ }^{37}$

No obstante la relación que existía entre la reflexión de los arbitristas portugueses y la discusión más amplia acerca del declive de la monarquía

32 Mendes da Luz, 1960, 3.

33 Thomaz, 1995, 481-519; Subrahmanyan, 1995, 113-125; Van Veen, 2000, 5-6; Winnius, 1985.

34 Bethencourt, 326-327.

35 Murteira, 2012, 275-293.

36 AGS, Estado, 2636, Sobre lo que escribe el virrey de Portugal en lo de la seguridad de las Indias orientales, 26 de abril de 1603; AGS, Estado, 435, 175, Sobre unas consultas del consejo de Portugal en lo del socorro de la India, 17 de octubre de 1607; AGS, Estado, 437, Sobre el mal estado en que están las cosas de la India, 29 de septiembre de 1620.

37 Además de los ya conocidos arbitristas que reflexionaron sobre la situación del Estado da Índia, como Francisco Rodrigues Silveira, el flamenco Jacques de Coutre y Duarte Gómez Solís, otros autores escribieron sobre la necesidad de reforma de las Indias Orientales. ANTT, Miscelâneas Manuscritas do Convento da Graça (MMCG), tomo 6F, Socorro que es mister per a restauração de la India Oriental, 63; Proposta de Rafael Carneiro de Alcáçova pera conservação do Estado da Índia Oriental, 70v.; Discurso en que se trata de los medios pera estorvar el trato que tienen los holandeses en la Índia, 88. 
hispánica, los autores que escribieron sobre las conquistas de origen luso fijaron su atención en los problemas y en las amenazas a las antiguas posesiones de Portugal. Esta preocupación se manifestó en la consolidación de un arbitrismo sobre el Estado da Índia y en una literatura específica sobre su declive durante el periodo de la unión de las coronas ibéricas.

Como hemos mencionado, la entronización de Felipe II como rey de Portugal en 1580-1581 fue contemporánea al nacimiento de una reflexión arbitrista sobre los problemas del conjunto de posesiones de la India. Esta inquietud fue predominante entre los arbitristas portugueses hasta por lo menos el inicio de la década de 1630. El ritmo de la producción de los arbitrios sobre los territorios americanos parece haber sido influenciado por dos factores principales: el propio declive de las posesiones orientales de origen portugués y la presencia de enemigos de la monarquía hispánica que amenazaban las regiones atlánticas. Era necesario alertar a los soberanos españoles de la importancia del Estado do Brasil, evitando el mismo destino de las Indias Orientales.

En la producción de los arbitrios sobre la América lusa es posible distinguir dos fases principales. La primera, comprendida entre finales del siglo XVI hasta cerca de 1625 , fue caracterizada por arbitrios que alertaban al monarca de problemas ocasionales de la monarquía, o le recomendaban de una forma general la conservación de Brasil en el conjunto de las posesiones del imperio español. Los textos del licenciado Domingos de Abreu de Brito y del sacerdote portugués Manuel de Andrada de Castelo Branco — redactados en la década de 1590 — son claros ejemplos de este tipo de análisis.

La segunda fase parece haber empezado en los primeros años de la década de 1620, y su desarrollo fue influenciado por las invasiones holandesas al noroeste de Brasil, primero de Bahía (1624) y después de Pernambuco (1630). Como señaló Guida Marques, la presencia holandesa en esta región fue un importante hito en la producción del discurso arbitrista en la América lusa ${ }^{38}$ En los escritos del prelado de Pernambuco Bartolomeu Ferreira Lagarto — redactados en la década de 1630 — y de los militares Juan Rabelo de Lima, Luís Álvares Barriga y Bento Maciel Parente - fechados probablemente entre 1625-1635-, son claras las preocupaciones sobre la estrategia de defensa y conservación de la América portuguesa, acentuadas después de la perdida de Bahía y Pernambuco.

38 Marques, 2008, 138. 


\section{El arbitrismo sobre la América portuguesa (1590-1625)}

En sus primeros años de servicio al rey en Bahía, donde ejerció el oficio de proveedor mayor de la hacienda real de la América lusa, Cristovão de Barros escribió al cardenal don Henrique un papel sobre «alguas cousas que convinhão» al servicio regio. El licenciado, que poco tiempo después fue enviado a la capitanía de Pernambuco para fomentar la recaudación fiscal, advirtió al soberano sobre los perjuicios que podría causar la concesión regia de una renta anual en azúcar a los jesuitas del colegio de Olinda. En su arbitrio, Barros también llamó la atención del soberano sobre la defensa de las posesiones portuguesas en América, y en especial resaltó la importancia de reforzar la capitanía de Pernambuco con un fuerte que evitase el riesgo de ataques de las embarcaciones francesas que frecuentemente rondaban la región. ${ }^{39}$

Al margen de la importancia de la carta de advertencias de Barros en la producción de los arbitristas sobre la América lusa, uno de los primeros arbitrios «modernos» sobre la situación del Brasil fue escrito por el licenciado Domingos de Abreu de Brito, magistrado que en 1590 fue nombrado por Felipe II para efectuar una inspección en la conquista. En su informe enviado al monarca, Abreu de Brito registró importantes informaciones sobre Angola, donde había estado anteriormente, y Brasil.

A pesar de la proximidad entre el escrito de Abreu de Brito y el género de relaciones que describían a la América portuguesa en este período, la obra de este autor planteó una serie de propuestas para los problemas que afectaban al Estado do Brasil a finales del siglo XVI, lo que permite considerarlo como uno de los primeros arbitrios sobre aquella posesión.

Entre los temas discutidos por Abreu estaban la ampliación de la hacienda real sin tributación de los vasallos y la necesidad de establecer fortificaciones en Bahía y Pernambuco. Su preocupación por las fortificaciones fue influenciada por la coyuntura de incursiones corsarias inglesas y francesas en el noroeste de Brasil. Como señaló el autor, para la seguridad de las conquistas era necesario aislar a la América portuguesa de «luteranos franceses, ingleses, rochalezes» y de individuos de todas las partes del norte de Europa. ${ }^{40}$

39 ANTT, Corpo Cronológico, parte. I, maço. 111, n. ${ }^{\circ}$ 64, Carta de Cristovão de Barros, provedor-mor da fazenda real do Brasil, informando o rei do prejuízo que a fazenda real tinha nos mil cruzados que doara ao colégio dos jesuítas de Olinda, 18 de deciembre de 1578.

40 Felner, 1931, 84. 
La temática de las fortificaciones y la conservación de la costa brasileña contra los ataques de corsarios también fue discutida por el sacerdote portugués Manoel de Andrada Castelo Branco, que en 1590 escribió un arbitrio para ser presentado a Felipe II. El escrito de Branco, que durante la década de 1560 había servido en Brasil, parece haber despertado alguna curiosidad. Este papel fue impreso en España, aunque no haya registros del lugar y la fecha exactos de la edición. En su arbitrio, Castelo Branco señaló al rey prudente que era preciso conservar no solo las conquistas ultramarinas, sino también la religión católica, orientando las fuerzas contra los ataques ingleses y franceses. Como afirmaba este autor,

todo el mar Océano navegable, es de V. Magestad [...] siendo defensor de la Fe, por la cual causa los paganos ingleses, y franceses le contrarían y roban en todo el mar océano, en todas sus navegaciones, ansi de Oriente, como de Poniente, haciéndose ricos y poderosos, para sustentar guerras contra la Iglesia Católica, y corona de V. Magestad. Para defensa de lo cual, apunto todos los remedios que abajo se dirán.

Ante los ataques «luteranos» a la costa brasileña, Felipe II debía garantizar la fortificación de las ciudades y los puertos más importantes de la América portuguesa, como los de Salvador y Río de Janeiro. La primera ya había sido foco de una incursión inglesa (1588), mientras que la segunda resultó ser el epicentro de la presencia francesa en Brasil durante la primera mitad del siglo XVI. ${ }^{41}$

No obstante el interés de los arbitristas, el Estado do Brasil fue pensado en conjunto con otras posesiones ultramarinas hasta los primeros años de la década de 1620. En este período, las relaciones de descripción del territorio y los arbitrios enviados a los reyes españoles señalaban sus riquezas naturales y la importancia que aquella conquista podría tener dentro del imperio español.

Esta visión general de este territorio en el contexto más amplio de las posesiones atlánticas parece haber sido influenciada por el predominio ejercido por las Indias Orientales en el conjunto de las posesiones lusas. Hasta el año de 1630, se puede decir que las Indias Orientales estaban en el centro de las preocupaciones y del «imaginario» imperial portugués. En este período, el Estado da Índia era tenido todavía como la principal fuente de las riquezas y las glorias portuguesas, resultado de la construcción del

41 El arbitrio de Castelo Branco fue publicado en una edición bilingüe español/inglés. Hair, 1990. El autor discutió el problema de las fortificaciones en los capítulos 2, 5, 9 y 10. 
mito de la «edad de oro» del Oriente. ${ }^{42}$ Por ejemplo, cuando en 1630 Antonio de Sousa de Macedo indicó a Felipe IV las riquezas de sus posesiones de origen portugués, no dudó en subrayar el fasto de las Indias Orientales: «sus conquistas ultramarinas son riquísimas, como es Brasil, Angola, Santo Tomé, Cabo Verde, y todas las más, principalmente la tierra de la India Oriental es llena de minas de diamantes, rubíes, y otras piedras preciosas, los frutos de la tierra».43

Aunque sobrevivió esta visión idílica sobre la India, las informaciones acerca de los recursos naturales de la América lusa también llegaban gradualmente a los monarcas españoles. En su diálogo Do sítio de Lisboa, publicado a principios del siglo XVII, Luís Mendes de Vasconcelos se refirió a la plata de las posesiones americanas: «Pois o Brasil não he esteril de prata; eu sei de pessoas, que o tem visto, e atentamente considerado, que lhe não faltam essas cousas».44

La presencia de oro y metales preciosos también fue señalada por la pluma de otros arbitristas que remitieron sus advertencias y propuestas a la corte madrileña. En 1616, por ejemplo, los consejeros de Estado analizaron el memorial del portugués João Mendes de Vasconcelos, que empezó su informe subrayando la necesidad de explotar el oro en Brasil, puesto que «es una de las más puras provincias de toda la América y aunque en ella hay muchas minas de oro, no se ha dado en otra ninguna granjería sino la de los azúcares». Además de su referencia al oro, Vasconcelos reflexionó sobre los remedios para combatir la acción de los piratas y los corsarios en Brasil, evitando las pérdidas constantes que suponían para la hacienda real. ${ }^{45}$

La interpretación del Estado do Brasil como parte del conjunto de las posesiones portuguesas estuvo presente en arbitrios sobre la necesidad de defender el territorio contra los holandeses y en los proyectos de modernización militar para las Indias Orientales y la Costa de Guinea. ${ }^{46}$

42 Valladares, 2001, 10.

43 Sousa de Macedo, 1631, cap. III, excelencia III, 22v.

44 Vasconcelos, 1786, 18.

45 AGS, Estado, 437-161, Pide se vean en el consejo de Estado los puntos que refiere con este memorial acerca de los daños que reciben de los piratas que tratan y contratan en el Brasil y asimismo el modo con que esto se puede remediar, 6 de julio de 1616 .

46 BNP, Cod. 1555, Providências a adoptar para a manutenção e expansão de Portugal e principalmente das suas conquistas, 138-139; ANTT, ML, 1126, Lourenço Brandão, Razões de estados políticos sobre a conservação dos reinos de Portugal por meio de uma lei pia em orden. Charidade, ivstica \& fortaleza, 14 de diciembre de $1622,1-18 \mathrm{v}$. 
A pesar de la importancia de sus antecedentes y de los escritos específicos sobre la América lusa, después de 1620 el arbitrismo sobre el Brasil logró un nuevo impulso. La recuperación de Bahía de manos de los holandeses en 1624 no solo generó una serie de relaciones de batalla y gestas, sino que también resultó un importante marco en el que se desarrolló la cultura escrita sobre el territorio y el discurso arbitrista. ${ }^{47}$ Además de las invasiones holandesas y de la recuperación del territorio brasileño, la reflexión arbitrista sobre las posesiones americanas también parece haber sido afectada por las pérdidas territoriales del Estado da Índia. En este contexto, se hizo necesario advertir al monarca español sobre la conservación de Brasil y su importancia estratégica.

\title{
La presencia holandesa y la conservación de Brasil (1625-1640)
}

En octubre de 1636, el cuarto Felipe reconoció la gravedad de la situación de la América portuguesa y de las conquistas lusas de su imperio:

\begin{abstract}
As couzas do Estado do Brasil e mais conquistas ultramarinas desse Reino e o aperto em que as tem posto os inimigo me obrigavão ao desvelo, e cuidado que é notório para tratar de todos os meios possíveis, para se fazerem as armadas em ordem a se desalojar o inimigo daquelas partes [...] e se prevenir a defensão desses reinos e conquistas. ${ }^{48}$
\end{abstract}

Después de la invasión holandesa de Bahía y Pernambuco, los debates acerca del socorro de Brasil adquirieron una importancia central en las reuniones del Consejo de Estado, compartiendo la atención de los ministros con los problemas de las posesiones orientales lusas. Un ejemplo de esta preocupación por Brasil fue la formación de una junta de gobierno realizada en los aposentos del conde-duque de Olivares.

La junta del valido tenía como principal finalidad discutir los «efectos donde se pueda sacar dinero» para la guerra, fortificaciones y socorros de Pernambuco. Además, sus miembros planearon el envío de una armada real para la expulsión de los neerlandeses. Con el asedio a Brasil, «infestado y oprimido» por naciones extranjeras de Europa, fue necesaria la movi-

47 Marques, 2009, 121-122.

48 BNP, Cod. 6916, Carta régia a D. João da Costa, 12 de octubre de 1636, 31-31v. 
lización de los cabildos municipales del reino y de las islas atlánticas para el socorro de este territorio y la conservación de la América portuguesa. ${ }^{49}$

Aunque hubiese consenso entre los consejeros de Madrid en cuanto a la necesidad de acudir a Brasil, entre los arbitristas no había unanimidad sobre la urgencia de recuperar aquella conquista. Por ejemplo, un arbitrio enviado al conde-duque en 1630 señalaba los inconvenientes, las dificultades y los costos de una jornada para recuperar Pernambuco. En la opinión del arbitrista, el envío del socorro al Brasil podría ocasionar el debilitamiento de las flotas de España, de las Indias Occidentales y de otras plazas, abriendo brechas para los enemigos de la monarquía hispánica. ${ }^{50}$ A pesar de las incertidumbres de la empresa, después de 1620 las preocupaciones por la recuperación y la conservación del Estado do Brasil originaron una serie de arbitrios, cuyos argumentos pueden ser divididos según sus objetivos generales o sus temáticas centrales. ${ }^{51}$

En primer lugar, fueron predominantes los autores que escribieron de una forma general sobre los medios para la «conservación» y la «recuperación» de la América lusa. Estos arbitristas optaron por una interpretación conjunta de las medidas que podían adoptarse para la recuperación de la conquista, sin teorizaciones y abstracciones sobre un único tema.

En 1634, el prelado de Pernambuco Bartolomeu Ferreira Lagarto redactó un arbitrio señalando la urgencia del socorro de Brasil, en especial de la capitanía. Según este autor, ante la imposibilidad de enviar una ayuda general el monarca debía mandar inmediatamente hasta veinte galeones con artillería y raciones..$^{52}$ Otro ejemplo de esta perspectiva general sobre la conservación de la conquista impulsada por la presencia holandesa fueron las advertencias del capitán Juan Rabelo de Lima, que apuntó sus consejos para «milhor se poder tratar do remédio que convén, a conservação do Brazil». En opinión de Rabelo de Lima, la recuperación de la América por-

49 AGS, Secretarias Provinciales, libro 1477, Cópia das duas relações que forão com a consulta que atrás fica reg. da. effectos donde se pode tirar dr. $^{\circ}, 5-7$; Renda fixa que há da fazenda de sua magestad livre de consignações, 7v-8; Cópia de hua consulta sobre a pessoa que há de fazer a armada do socorro do Brazil, e a formar hua junta p. ${ }^{a}$ cobrança de dr. ${ }^{o}$ p. ${ }^{a}$ ella e outros particulares, 20 de junio de 1631, 8v-12.- ANTT, CFA, 21, Sobre uma carta de Filipe III de Portugal a Miguel de Vasconcelos sobre o socorro do Brasil, 225v-226v.

50 Biblioteca Geral da Universidade de Coimbra (BGUC), Mss. 491, Parecer político que se dio al valido de España para Felipe IV que se apuntan los inconvenientes, que se ofrecen en la jornada y socorro de Pernambuco, en la coyuntura presente del año de 1630, 134-137v.; ANTT, ML, 844,. 236-249.

51 Vilar Berrogain, 1973, 196-238; Gutiérrez Nieto, 1986, 236-238.

52 BNE, Mss. 3015, Apuntamientos a un papel de advertencias tocantes al socorro del estado del Brasil, por el doctor B.me fr. ${ }^{a}$ Lagarto, administrador que fue de aquel distracto, 9-12v. 
tuguesa debía partir de tres consideraciones esenciales: el impacto de las rentas del Estado do Brasil en la hacienda real de Portugal, la importancia de los señores de ingenios azucareros para la supervivencia de la hacienda real en Brasil, y la necesidad de proteger a estos productores de azúcar para que posteriormente contribuyesen al fisco. ${ }^{53}$

Entre los autores que teorizaron de manera más amplia sobre el Estado do Brasil, Luís Álvares Barriga merece destacarse. Este arbitrista, que ya había demostrado sus habilidades con la pluma en ocasiones distintas, ejemplifica el cambio de prioridades de la corona portuguesa en relación a aquel territorio. El caballero portugués, que a través de sus arbitrios había reflexionado sobre las posibilidades de recuperar Ormuz después de 1622, en la década siguiente analizó la situación de la América lusa en distintas ocasiones..$^{54}$

Entre 1631 y 1635 Barriga redactó una serie de arbitrios que fueron remitidos al conde-duque de Olivares. Como señaló Guida Marques, Barriga representaba efectivamente la figura del arbitrista, proponiendo sus remedios para los problemas de los territorios americanos de la Corona de Portugal ${ }^{55}$ En su Propuesta de las advertencias..., Barriga respondió a los que sospechaban de sus proyectos y reflexionó sobre los medios necesarios para la recuperación de Pernambuco, sobre el comercio marítimo y sobre la conservación del Estado do Brasil. El arbitrista concebía una unión de fuerzas marítimas y terrestres para que el soberano lograse un resultado más amplio: «la milicia y armada que tengo propuesta atienden no solamente a defender y conservar las conquistas y el comercio, más juntamente a recuperar lo perdido con mucha seguridad y sertesa, y assí tengo satisfecha la objeción». ${ }^{56}$

Pero los arbitristas que escribieron sobre la América portuguesa también produjeron textos sobre temáticas específicas, como por ejemplo un arbitrio técnico anónimo sobre los medios de extracción de plata en la capitanía de Sergipe del Rey. ${ }^{57}$ Otro ejemplo de la diversidad fueron las propuestas fiscales que planteaban nuevos medios de ingreso para la hacienda

53 BNE, Mss. 2436, Papel de Juan Rabelo de Lima sobre a conservação e defensão do Estado do Brazil, 1630, 105.

54 ANTT, ML, 1116, Discurso sobre a empresa de Ormuz e pareceres que facilitam a sua recuperação, feito por Luís Álvares Barriga, 538-544.

55 Marques, 2009, 143.

56 Barriga, en Anais da Biblioteca Nacional do Rio de Janeiro, 69, 1950, 287.

57 «Modo e artifícios de beneficiar a prata desde a hora em que se tira da minha em que nace até se poder lavrar pella arte do ourives ou bater», en Salvado y Miranda, 2001, 59. 
real y su empleo en el socorro de Brasil. Un papel anónimo enviado por un supuesto sacerdote a la virreina Margarita de Saboya explicaba cómo sacar dinero de Portugal para el incremento de la armada y el socorro de Brasil. Ante la situación fiscal del reino era necesario no «oprimir» al pueblo, y el arbitrio establecía un medio de hacer tributar a los vasallos sin presionar al reino, protegiendo la imagen real de las críticas. En opinión del autor, los ingresos de los arzobispados libres, la reducción de universidades, o la confiscación de los bienes de presos por deudas y de las rentas eclesiásticas consignadas a hijos de mercaderes judíos, podrían ser usados para la recuperación de la conquista. ${ }^{58}$

Además del socorro de Brasil, los arbitrios fiscales proponían la extracción de recursos coloniales para aplicarlos en el reino y en el comercio atlántico. Un escrito anónimo sobre esta temática subrayó la importancia que los diezmos de la América portuguesa podrían tener en la hacienda real y su «utilidad» para la formación de una armada que resguardase las flotas lusas que iban a Brasil para recoger mercancías. ${ }^{59}$

En 1629, otro arbitrio fiscal de un autor no identificado explicaba como el monarca podría sacar una «gran cantidad» de ducados del Estado do Brasil. Según este autor, el monarca debía enviar a un magistrado de su confianza para que vendiese perdones a los condenados, cobrando una cantidad proporcional al delito cometido. En caso de una nueva infracción, la hacienda real podría lograr más ingresos con la venta de perdones generales para todas las trasgresiones cometidas. Además del comercio de indultos, el arbitrista también planteó la comercialización de hidalguías para recaudar fondos y su empleo en los galeones de resguardo de las flotas de Brasil. ${ }^{60}$

No obstante la heterogeneidad de asuntos discutidos por los arbitristas sobre la América portuguesa, tanto las fortificaciones como la navegación recibieron una atención especial. En una coyuntura de dominio holandés en la cual era necesario recuperar Pernambuco y conservar las capitanías que todavía quedaban dentro de la jurisdicción del monarca portugués, la urgencia por obtener resultados concretos superó las grandes teorías y las abstracciones arbitristas.

58 BNP, Mss. 208, n. ${ }^{\circ}$ 12, Propuesta de un sacerdote sobre la conquista del Brasil y los efectos que se podrán aplicar para ella.

59 Salvado y Miranda, 2001, 47-54.

60 ANTT, Desembargo do Paço, Repartição de Justiça e Despacho de Mesa, livro 12, Memoria de como se podrá sacar una gran cantidad de ducados del estado del Brasil para su mag. ${ }^{\mathrm{d}}$ sin ser contra su servicio, antes en bien de los vasallos, 109. 
Acerca de las fortificaciones, además de las advertencias de los arbitrios con temáticas más generales, en 1630 el religioso Bartolomeu Ferreira Lagarto redactó un papel con diversas propuestas para la conservación de la América portuguesa. El autor llamó la atención sobre la necesidad de fortificar otras capitanías reales y también las que estaban en la jurisdicción de donatarios particulares. Según su opinión, los recursos naturales de Brasil podían ser usados en los proyectos de defensa de la conquista, como por ejemplo la utilización de maderas para la construcción de bajeles. ${ }^{61}$

La preocupación por la acción militar de las posesiones americanas igualmente generó un arbitrio acerca de la conveniencia y la utilidad de fortificar Río de Janeiro. Ante las sospechas de una invasión neerlandesa al sudeste de Brasil, un arbitrista anónimo decidió reflexionar sobre el proyecto de guarnecer la ciudad, proponiendo la construcción de una fortaleza en su parte más alta. ${ }^{62}$ La discusión sobre el control de los mares fue debatida en diferentes arbitrios que trataban asuntos como la seguridad del transporte marítimo, la defensa de la costa brasileña o el envío de armadas para la recuperación de Pernambuco.

En un papel escrito pocos días después de que llegara la noticia de la caída de Pernambuco en manos de los holandeses, el ya citado Bartolomeu Lagarto recalcó la necesidad de despachar galeones para la seguridad del transporte del azúcar. Según Lagarto, el envío de embarcaciones era esencial no solamente para garantizar la supervivencia del comercio atlántico, sino también para el incremento de las aduanas y los derechos reales. Además del transporte de mercancías, Lagarto subrayó la urgencia de socorrer Pernambuco para frenar nuevas incursiones corsarias y holandesas. ${ }^{63}$

El capitán portugués Bento Maciel Parente remitió un arbitrio a la junta del conde-duque en el que planteaba el establecimiento de una fábrica naval en Brasil para las armadas y la navegación de las Indias. En su propuesta, Parente señaló la importancia de los recursos naturales de las distintas regiones de la América portuguesa y su gran potencial para la industria naval. Su plan comprendía la construcción de galeones en Brasil en sus diferentes etapas. Finalmente, el capitán concluyó su memorial instando al

61 BNE, Mss. 2362, Para la recuperación de la Plaza de Pernambuco ocupada por los Olandeses, 269-273; ANTT, ML, 1116, Copia del discurso relativo de las razones que se ofrecen, unas para que el holandés se haya de fortificar en la Bahía y otras para que no aserlo, 701-711.

62 «Discurso sobre a conviniência da fortificação da montanha desta cidade do Rio de Janeiro», en Salvado y Miranda, 2001, 64-70.

63 BNE, Mss. 2362, Advertencias para la conservación del comercio en Pernambuco, y destrucción del Olandes con las respuestas a las advertencias, 261-262. 
monarca a que concediese la atención requerida por los problemas de la América portuguesa, «antes que el daño sea mayor e irreparable». ${ }^{64}$

La presencia holandesa en Brasil también propició arbitrios acerca de sus actividades de corso en la costa de Portugal, en Brasil y en el espacio atlántico. En el «memorial do Estado do Brasil», los señores de ingenios y habitantes de aquel estado reclamaban soluciones al monarca contra la acción de los corsarios y el incremento de la seguridad de la América portuguesa. En este sentido, los vasallos solicitaban al soberano el envío de doce naos armadas para garantizar la seguridad del transporte azucarero, la navegación atlántica y los derechos de la hacienda real. ${ }^{65}$

\section{Conclusión}

Como hemos visto, a lo largo del período de unión de las coronas ibéricas los arbitristas tuvieron un papel central en las discusiones acerca de la conservación de la América portuguesa. A pesar de esto, en comparación con la producción de los arbitristas que escribieron sobre el Estado da Índia, las posesiones americanas parecen haber recibido una atención secundaria.

En el contexto más amplio de los territorios de la monarquía hispánica, las posesiones de origen luso mantuvieran cierto nivel de autonomía debido al estatuto logrado por Portugal en las cortes de Tomar. Esta autonomía puede haber sido determinante para el desarrollo de una reflexión específica sobre los problemas de los territorios de la corona portuguesa. Aunque los arbitristas que escribieron sobre el contexto luso participaron de la «introspección colectiva» acerca del declive de la monarquía compuesta de los Austrias, los problemas del Estado da Índia y de la América portuguesa parecen haber sido un asunto central en la reflexión de estos autores. ${ }^{66}$

Dentro de esta tradición arbitrista referida a las conquistas portuguesas, hasta el año 1630, por lo menos, el Estado da Índia fue el tema más relevante de los memoriales. Si bien los arbitrios sobre la América lusa habían sido enviados a los soberanos españoles desde finales del siglo XVI, la producción específica sobre Brasil ganó un nuevo desarrollo después de

64 «Papel que se remitió a la junta del padre confesor sobre la fábrica de los navíos del Brasil», en Salvado y Miranda, 2001, 60-64.

65 «Memorial do estado do Brasil para sua Magestade», «Papel de Pernambuco sobre o remedio que se deve dar a que vão e venhãon navios en frota aconpanhados de hua armada, e como isto se deve fazer», en Salvado y Miranda, 2001, 376-389.

66 Elliott, 1977, 41-61. 
las invasiones holandesas de Bahía y Pernambuco. En relación a los temas y las preocupaciones de los arbitristas que se dedicaron a la reflexión sobre los problemas del Estado do Brasil durante la unión de las coronas ibéricas, es posible distinguir dos momentos principales. En el primero, comprendido entre 1590 y 1625, los arbitristas incluyeron a la América portuguesa en el conjunto de los territorios atlánticos de origen luso. En este período, el tema de las fortificaciones de la conquista fue predominante, demostrando la inquietud de los autores por las incursiones francesas e inglesas en la costa brasileña. No obstante la importancia de estos arbitrios, en este momento la defensa de la América portuguesa todavía no era el problema más importante, circunstancia que cambiaría con la invasión holandesas a Bahía en 1624.

En un segundo momento, a raíz de la presencia de los holandeses y de la pérdida gradual de las posesiones orientales lusas, el Estado do Brasil pasó a ocupar el lugar más destacado entre los territorios portuguesas de Felipe IV. Además de los relatos, gestas y representaciones de la restauración de Bahía, los arbitristas colocaron sus habilidades al servicio de la conservación de la conquista. De esta manera, la producción de arbitrios sobre la América portuguesa se desarrolló efectivamente después de 1630, cuando los autores reflexionaron sobre la situación de Brasil con una mayor diversidad temática y conceptual.

Después de la secesión de 1640, este arbitrismo logró un nuevo impulso. Con la aclamación de don Juan IV, los consejos de la corona portuguesa rescataron su sentido original. En este sentido, las instituciones de gobierno, como el Consejo de Estado y las cortes recobraron su poder para resolver los asuntos portugueses. Además de la restauración de los canales ordinarios de decisión política, el nuevo rey de Portugal ordenó la creación del Consejo Ultramarino para el tratamiento de las cuestiones de las conquistas. Ante a los cambios institucionales ocurridos en los primeros años de la restauración, los arbitristas ampliaron su espacio de comunicación política con el monarca, lo que señaló una nueva etapa del arbitrismo luso. Influenciados por el debate acerca de las prioridades ultramarinas de la dinastía de los Braganza, los arbitristas reflexionaron sobre las medios de recuperar el Estado da Índia y acerca de la conservación del Estado do Brasil. ${ }^{67}$

67 Barros, 2008. 


\section{VINICIUS DANTAS}

\section{Bibliografía}

Amorim, Inês: «Manuel Severim de Faria: uma releitura dos remédios para a falta de gante. 1655», Revista da Faculdade de Letras da Universidade do Porto, 5, Porto, 1988, 151-172.

Amzalak, Moses Bensabat: A economia política em Portugal, o Economista Duarte Gomez de Solis, Lisboa, Impresso nas Oficinas Graficas do Museu Comercial, 1922a.

Amzalak, Moses Bensabat: A economia política em Portugal, Os estudos económicos de Manuel Severim de Faria, Lisboa, Impresso nas Oficinas Graficas do Museu Comercial, 1922b.

Anais da Biblioteca Nacional do Rio de Janeiro, 69, Rio de Janeiro, 1950.

Andrada Castel Branco, Manoel de y Hair, Paul Edward Hedley (eds.): To defend your empire and the faith. Advice offered to Philip, King of Spain and Portugal, c. 1590, Liverpool University Press, 1990.

Archivo portuguez oriental, fasc. 3. ${ }^{\circ}, 2^{a}$ parte, Nova Goa, Imprensa Nacional 1861.

Barros, Edval de Souza: Negócios de tanta importância. O conselho ultramarino e a disputa pela condução da guerra no Atlântico e no Índico (1643-1661), Lisboa, Centro de História de Além-Mar, 2008.

Bethencourt, Francisco: «O complexo atlântico», en Bethencourt, Francisco y Chaudhuri, Kirti (dirs), História da Expansão Portuguesa, 2, Lisboa, Circulo de Leitores, 1998, 315-342.

Bluteau, Rafael: Vocabulário portuguez \& latino, 1, Lisboa, Oficina de Pascoal da Silva, 1716.

Borelli, Gianfranco: Ragion di stato e leviatano: Conservazione e scambio alle origini della modernita política, Bologna, Il Mulino, 1993.

Cabral de Mello, Evaldo: Olinda restaurada. Guerra e açúcar no Nordeste, 1630 1654, São Paulo, Editora 34, 2007.

Ceballos, Rodrigo: Arribadas Portuguesas: A participação Luso-Brasileira na constituição social de Buenos Aires, (c.1580-c.1650), Tese de Doutorado em História, Universidade Federal Fluminense, 2008.

Coelho, António Borges: «O mercantilista Duarte Gomes Solis: análises e modelos dirigidos ao governo filipino», Arquipélago, História, 2. ${ }^{\text {a }}$ serie, 1-1, Azores, 1995, 161-179.

Coelho, António Borges: «Duarte Gomes Solis: Portugal e o império», Separata da Academia de Marinha, Lisboa, 1996.

Costa, André da Silva: Os secretários e o estado do rei - luta de corte e poder político, secs XVI-XVII, Dissertação de Mestrado em História Moderna, Universidade Nova de Lisboa, 2008.

Cruz, Maria Leonor Garcia da: Lourenço Pires de Tavora e a política portuguesa no norte de África no século de quinhentos, Dissertação de Mestrado em História, Faculdade de Letras da Universidade de Lisboa, 1988. 
Cruz, Maria Leonor Garcia da: «As controvérsias ao Tempo de D. João III sobre a política Portuguesa no Norte de África», Mare Liberum, 13, Lisboa, 1997, 123-199.

Curto, Diogo Ramada: O discurso político em Portugal (1600-1650), Lisboa, Universidade Aberta, 1988a.

Curto, Diogo Ramada: «A economía política no tempo do alvitrismo», en Cardoso, José Luís (org.), Contribuições para a História do Pensamento Económico em Portugal, Lisboa, Publicações Dom Quixote, 1988b, 17-21.

Curto, Diogo Ramada: «Cultura escrita e práticas de identidade», en Bethencourt, Francisco y Chaudhuri, Kirti (dirs), História da Expansão Portuguesa, 1, Lisboa, Circulo de Leitores, 1998, 458-531.

Curto, Diogo Ramada: «Remédios ou arbítrios», en Curto, Diogo Ramada, Cultura imperial e projetos coloniais (séculos XV a XVIII), São Paulo, Editora da Unicamp, 2009, 177-193.

Curto, Diogo Ramada: «Remédio para os males» en Curto, Diogo Ramada, Cultura política no tempo dos Filipes (1580-1640), Lisboa, Edições 70, 2011a, 347-400.

Curto, Diogo Ramada: «Cortes políticas», en Ibidem, 2011b, 473-484.

Dubet, Anne y Sabatini, Gaetano: «Arbitristas: acción política y propuesta económica», en Martínez Millán, José y Visceglia, Maria Antonietta (dirs.), La monarquía de Felipe III: La corte, 3, Madrid, Fundación Mapfre, 2008, 867-883.

Elliott, John: «Self-Perception and Decline in Early Seventeenth-Century Spain», Past \& Present, 74, Oxford, 1977, 41-61.

Elliott, John: El conde-duque de Olivares. El político en una época de decadencia, Barcelona, Crítica, 2009.

Felner, Alfredo de Albuquerque y Brito, Domingos de Abreu: Um inquérito à vida administrativa e económica de Angola e do Brasil em fins do século XVI, segundo o manuscrito inédito existente na Biblioteca Nacional de Lisboa, Coimbra, Imprensa da Universidade, 1931.

Flores, Jorge: Os olhos do rei: Desenhos e descrições Portuguesas da ilha de Ceilão (1624-1638), Lisboa, Comissão Nacional para as Comemorações dos Descobrimentos Portugueses, 2001.

Frutuoso, Eduardo: «Macau e Manila no Arbitrismo Ibérico», Revista de Cultura, Edição internacional, 23, 2007, 117-144.

Gama, Maria Luísa Marques da: O conselho de Estado no Portugal restauradoteorização, orgânica e exercício do poder político na corte brigantina (16401706), Dissertação de Mestrado em História Moderna, Universidade de Lisboa, 2012.

Gil Pujol, Xavier: «Las fuerzas del Rey. La generación que leyó a Botero», en Ruiz Ibáñez, José Javier; Rizzo, Mario y Sabatini, Gaetano (coords.), Le forze del príncipe: recursos, instrumentos y límites en la práctica del poder soberano 


\section{VINICIUS DANTAS}

en los territorios de la monarquía hispánica, 2, Murcia, Cuadernos del Seminario Floridablanca, 2003, 969-1022.

Godinho, Vitorino Magalhães: «Alguns problemas da economia portuguesa no século XVII de depressão internacional», Revista de História Econômica e Social, 5, Lisboa, 1980, 105-123.

Gutiérrez Nieto, Juan Ignacio: «El pensamiento económico, político y social de los arbitristas», en Menéndez Pidal, Ramón (ed.), Historia de España Menéndez Pidal. El siglo del Quijote (1580-1640). Religión, filosofía, ciencia, XXIV-1, Madrid, Espasa Calpe, 1986, 234-351.

Herzog, Tamar: «El arbitrismo y América», en Martínez Millán, José y Visceglia, María Antonia (dirs.), La monarquía de Felipe III: La corte, 3, Madrid, Fundación Mapfre, 2008, 925-931.

Luxán Meléndez, Santiago de: La Revolución de 1640 en Portugal. Sus fundamentos sociales y sus caracteres nacionales. El consejo de Portugal: 1580-1640, Tesis de doctorado, Madrid, Universidad Complutense, 1988.

Luz, Francisco Paulo Mendes da (ed.): Livro das cidades, e fortalezas, Qve a coroa de Portvgal tem nas partes da India e das capitanias, e mais cargos que nelas há, e da importancia delles, Lisboa, Centro de Estudos Históricos Ultramarinos, 1960.

Macedo, Antonio de Sousa de: Flores de España, excelencias de Portugal... [1631], Coimbra, Officina de Simoens Ferreyra, 1737.

Marques, Guida: «O Estado do Brasil na União Ibérica: dinâmicas políticas no Brasil do tempo de Filipe II de Portugal», Penélope, 27, Lisboa, 2003, 7-35.

Marques, Guida: L'invention du Brésil entre deux monarchies. Gouvernement et pratiques politiques de l'Amérique portugaise dans l'union ibérique (1580-1640), Tesis de doctorado, Paris, EHESS, 2009.

Martínez Torres, José Antonio: «Discurso y política en el África ibérica (siglos XVI y XVII)», en Las monarquías ibéricas: Barroco y globalización (15801715), Madrid, UNED, 2012.

Monteiro, Rodrigo Bentes: O rei no espelho: a monarquia portuguesa e a colonização da América (1640-1720), São Paulo, Hucitec, 2002.

Monumenta Henricina, Coimbra, Comissão executiva das Comemorações do V Centenário da Morte do Infante D. Henrique, 1971.

Murteira, André: «El impacto de la tregua de los doce años en los dominios ultramarinos portugueses», en García García, Bernardo J.; Herrero Sánchez, Manuel y Hugon, Alain (dirs.), El arte de la prudencia. La Tregua de los doce años en la Europa de los Pacificadores, Madrid, Fundación Carlos de Amberes, 2012, 275-293.

Oliveira, António de: «Álvaro Ferreira de Vera, Arbitrista», Revista Portuguesa de História, XIX, Coimbra, 1982, 271-296.

Olivera, António de: Poder e oposição política em Portugal no período Filipino (1580-1640), Lisboa, Difel, 1990. 
Parker, Geoffrey (coord.): La crisis de la monarquía de Felipe IV, Barcelona, Editorial Crítica, 2006.

Pereyra, Bento: Thesouro da lingoa portuguesa, Lisboa, Officina de Paulo Craesbeeck, 1647.

Rebelo, Luís de Sousa: «Damião de Gois, Diogo de Teive e os arbitristas do século XVII», Hvmanitas, 43-44, Coimbra, 1991-1992, 203-216.

Relação da aclamação que se fez na capitania do Rio de Janeiro do Estado do Brasil e nas mais do sul ao senhor rei Dom João IV, Lisboa, Jorge Rodrigues, 1641.

Rodrigues Silveira, Francisco: Reformação da milícia e governo do estado da Índia Oriental, Lisboa, Fundação Oriente, 1996.

Salvado, João Paulo y Miranda, Susana Münch (eds.): Livro primeiro do governo do Brasil, 1607-1633, Lisboa, Comissão Nacional para as Comemorações dos Descobrimentos Portugueses, 2001.

Schaub, Jean-Frédéric: «L'État quotidien entre arbitrisme et révolte, la gabelle au temps du comte-duc d'Olivares», en Schaub, Jean-Frédéric (dir.), Recherche sur l'histoire de l'État dans le monde ibérique (XVe-XXe siècle), Paris, Presses de 1 École Normale Supérieure, 1993, 21-50.

Schaub, Jean-Frédéric: Le Portugal au temps du comte-duc d'Olivares (16211640): Le conflict de juridictions comme exercice de la politique, Madrid, Casa de Velázquez, 2001.

Sérgio, António: Antologia dos economistas Portugueses, Século XVII, Lisboa, Livraria Sá da Costa Editora, 1974.

Silva, António de Morais: Diccionario da lingua portugueza, 1, Lisboa, Typographia Lacerdina, 1789.

Skinner, Quentin: «From the state of princes to the person of the state», en Visions of Politics, Renaissance Virtues, 2, Cambridge University Press, 2002, 368-413.

Solís, Duarte Gomez: Discursos sobre los comercios de las dos Indias, donde se tratan materias importantes de Estado, y Guerra, [Madrid], 1622.

Subrahmanyam, Sanjay: O império asiático Português, 1500-1700, Lisboa, Difel, 1995.

Thomaz, Luís Filipe F. R.: «A crise de 1565-1575 na História do Estado da Índia», Mare Liberum, 9, Lisboa, 1995, 481-519.

Trujillo, Oscar José: «Facciones, parentescos y poder: La élite de Buenos Aires y la rebelión de Portugal de 1640», en Yun Casalilla, Bartolomé (ed.), Las redes del imperio. Elites sociales en la articulación de la monarquía hispánica, 1492-1714, Madrid, Marcial Pons, 2009, 333-350.

Trujillo, Oscar José: «Integración y conflicto en una élite fronteriza: Los portugueses en Buenos Aires a mediados del siglo XVII», en Cardim, Pedro; Soares, Mafalda y Costa, Leonor Freire (orgs.), Portugal na monarquia hispânica. Dinâmicas de integração e conflito, Lisboa, Ed. CHAM / CIDEHUS / GHES / Red Columnaria, 2013, 249-269. 


\section{VINICIUS DANTAS}

Valladares, Rafael: «El Brasil y las Indias españolas durante la sublevación de Portugal (1640-1668)», Cuadernos de Historia Moderna, 14, Madrid, 1993, 151-172.

Valladares, Rafael: La rebelión de Portugal. 1640-1680, Guerra, conflicto y poderes en la monarquía hispánica, Junta de Castilla y León, 1998.

Valladares, Rafael: Castilla y Portugal en Asia (1580-1680), Declive imperial y adaptación, Leuven, Leuven University Press, 2001.

Van Veen, Ernst: Decay of Defeat? An inquiry into the Portuguese decline in Asia 1580-1645, Leiden, Research School of Asian, African and Amerindian Studies, Universiteit Leiden, 2000.

Vasconcelos, Luis Mendes de: De sitio de Lisboa: sua grandeza, povoação, e commercio [1608], Lisboa, Francisco Luiz Ameno, 1786.

Vasconcelos, Luis Mendes de (ed.): Como remediar o estado da Índia: being the appendices of the Vida de Jacques de Coutre (Biblioteca Nacional, Madrid, ms. 2780), Leiden, Center for the History of European Expansion, 1989.

Vilar Berrogain, Jean: Literatura y economía. La figura satírica del arbitrista en el Siglo de Oro, Madrid, Revista de Occidente, 1973.

Winnius, George D.: The black legend of Portuguese India. Diogo do Couto, his contemporaries and the Soldado Prático. A contribution to the study of political corruption in the empires of early modern Europe, New Delhi, Concept Publishing Company, 1985. 